\title{
Modeling the aggregated exposure and responses of bowhead whales Balaena mysticetus to multiple sources of anthropogenic underwater sound
}

William T. Ellison ${ }^{1}$, Roberto Racca ${ }^{2}$, Christopher W. Clark ${ }^{3}$, Bill Streever ${ }^{4}$, Adam S. Frankel ${ }^{5, *}$, Erica Fleishman ${ }^{6}$, Robyn Angliss ${ }^{7}$, Joel Berger ${ }^{8,9,16}$, Darlene Ketten $^{10}$, Melania Guerra ${ }^{3,17}$, Matthias Leu ${ }^{11}$, Megan McKenna ${ }^{12}$, Todd Sformo ${ }^{13}$, Brandon Southall ${ }^{14}$, Robert Suydam ${ }^{13}$, Len Thomas ${ }^{15}$

${ }^{1}$ Marine Acoustics, Inc., PO Box 6698, Portsmouth, NH 03802, USA

${ }^{2}$ JASCO Applied Sciences, Suite 2305, 4464 Markham St., Victoria, BC V8Z 7X8, Canada

${ }^{3}$ Cornell Lab of Ornithology, 159 Sapsucker Woods Rd., Ithaca, NY 14850, USA

${ }^{4}$ LAMA Ecological, 4311 Edinburgh Drive, Anchorage, AK 99502, USA

${ }^{5}$ Marine Acoustics, Inc., 4350 Fairfax Drive, Suite 600, Arlington, VA 22203, USA

${ }^{6}$ John Muir Institute of the Environment, The Barn, One Shields Ave., University of California, Davis, CA 95616, USA

${ }^{7}$ National Marine Mammal Laboratory, AFSC / NMFS / NOAA, 7600 Sand Point Way NE, Seattle, WA 98103, USA

${ }^{8}$ Division of Biological Sciences, University of Montana, Missoula, MT 598011, USA

${ }^{9}$ North American Program, Wildlife Conservation Society, Bozeman, MT 59715, USA

${ }^{10}$ Curtin University, Kent St., Bentley, WA 6102, Australia

${ }^{11}$ Department of Biology, College of William and Mary, 540 Landrum Dr., Williamsburg, VA 23185, USA

${ }^{12}$ National Park Service, Natural Sounds and Night Skies Division, 1201 Oakridge Drive, Fort Collins, CO 80525, USA

${ }^{13}$ North Slope Borough, Box 69, Barrow, AK 99723, USA

${ }^{14}$ Southall Environmental Associates, Inc., 9099 Soquel Drive, Suite 8, Aptos, CA 95003, USA

${ }^{15}$ Centre for Research into Ecological and Environmental Modeling and School of Mathematics and Statistics, University of St. Andrews, The Observatory, St. Andrews KY16 9LZ, UK

${ }^{16}$ Present address: Department of Fish, Wildlife and Conservation Biology, Colorado State University, 1474 Campus Delivery, Fort Collins, CO 80523, USA

${ }^{17}$ Present address: Applied Physics Lab, University of Washington, 1013 NE $40^{\text {th }}$ St., Seattle, WA 98105, USA

ABSTRACT: Potential responses of marine mammals to anthropogenic underwater sound are usually assessed by researchers and regulators on the basis of exposure to a single, relatively loud sound source. However, marine mammals typically receive sounds from multiple, dynamic sources. We developed a method to aggregate modeled sounds from multiple sources and estimate the sound levels received by individuals. To illustrate the method, we modeled the sound fields of 9 sources associated with oil development and estimated the sound received over $47 \mathrm{~d}$ by a population of 10000 simulated bowhead whales Balaena mysticetus on their annual migration through the Alaskan Beaufort Sea. Empirical data were sufficient to parameterize simulations of the distribution of individual whales over time and their range of movement patterns. We ran 2 simulations to estimate the sound exposure history and distances traveled by bowhead whales: one in which they could change their movement paths (avert) in response to set levels of sound and one in which they could not avert. When animals could not avert, about $2 \%$ of the simulated population was exposed to root mean square (rms) sound pressure levels (SPL) $\geq 180 \mathrm{~dB}$ re $1 \mu \mathrm{Pa}$, a level that regulators in the U.S. often associate with injury. When animals could avert from sound levels that regulators often associate with behavioral disturbance (rms SPL $>160 \mathrm{~dB}$ re $1 \mu \mathrm{Pa}$ ), $<1 \%$ of the simulated population was exposed to levels associated with injury. Nevertheless, many simulated bowhead whales received sound levels considerably above ambient throughout their migration. Our method enables estimates of the aggregated level of sound to which populations are exposed over extensive areas and time periods.

KEY WORDS: Arctic - Cumulative effects - Harassment - Incidental take - Marine mammals · Negligible impact 


\section{INTRODUCTION}

Anthropogenic underwater sounds from activities such as seismic exploration for oil and gas, commercial shipping, and operation of offshore oil platforms and wind turbines can reduce the condition and fitness of marine mammals. In some cases these sounds may cause temporary or permanent loss of hearing or shifts in hearing thresholds (reviewed in Southall et al. 2007). Exposure to chronic and impulsive underwater sounds also can increase levels of stress hormones (Rolland et al. 2012) and change behaviors associated with migration (McDonald et al. 2012), acoustic communication (Holt et al. 2011, Blackwell et al. 2013), diving (Costa et al. 2003, Tyack et al. 2011), and foraging (Goldbogen et al. 2013). Anthropogenic underwater sounds may decrease the ability of marine mammals to recognize either conspecific sounds or sounds used to perceive the environment, find prey, or avoid predators (Ellison et al. 1987a, George et al. 1989, Clark et al. 2009). Underwater sounds associated with certain sonar systems have been implicated as the cause of strandings of multiple species of beaked whales (D'Amico et al. 2009). Additionally, changes in the distribution or behavior of marine mammals in response to anthropogenic sound may reduce the availability of those animals to subsistence hunters in Alaska. The US Marine Mammal Protection Act (MMPA) (16 USC 1361-1423) prohibits activities that will have an 'unmitigable adverse impact' on subsistence uses 'by any Indian, Aleut, or Eskimo who resides in Alaska and who dwells on the coast of the North Pacific Ocean or the Arctic Ocean.'

The anthropogenic underwater sounds detectable at any one location often emanate from multiple sources. However, assessments of the potential responses of marine mammals to anthropogenic sound typically evaluate responses to a single, relatively loud source, such as sonar or an airgun array from a particular ship. Attempts to assess responses to aggregated sounds, or responses to the aggregated biological effects of sound from multiple sources, have seldom progressed beyond a statement of need and, occasionally, qualitative descriptions. For example, the German government examined the potential effects of seismic research on Antarctic marine ecosystems, acknowledging the challenges of rigorously assessing the potential environmental effects of sound (Siebert et al. 2012). Similarly, Moore et al. (2012) summarized major anthropogenic sources of sound in the Arctic Ocean and potential mechanisms by which marine mammals and their prey may respond physiologically or behaviorally. Moore et al. (2012) proposed that aggregated sound fields from human activities and natural phenomena be mapped and compared to spatial data on the distribution and abundance of marine mammals at different life stages. Another effort supported by federal agencies in the U.S. mapped distributions of cetaceans and anthropogenic underwater sound throughout the country's exclusive economic zone, including the Alaskan Arctic (NOAA 2012). Although these maps illustrated that some species of marine mammals occupy regions with substantial levels of underwater anthropogenic sound, the effort did not document contributions to the acoustic environment from individual sources of sound, the distribution of individuals and populations as the acoustic environment changed over time and space, or the levels of sound to which animals were exposed as their acoustic environment changed.

Biological responses to aggregated sound exposure are highly relevant to decision-making about diverse human activities in marine ecosystems. The National Marine Fisheries Service (NMFS) of the US National Oceanic and Atmospheric Administration (NOAA), which is charged with implementing the MMPA as it applies to pinnipeds and cetaceans, currently considers a received root mean square (rms; essentially an average over the duration of a pulse or over a short, fixed period for non-pulse sounds) sound pressure level (SPL; in $\mathrm{dB}$ re $1 \mu \mathrm{Pa}) \geq 160 \mathrm{~dB}$ for impulsive sounds and $\geq 120 \mathrm{~dB}$ for continuous sounds as thresholds beyond which behavioral patterns of pinnipeds and cetaceans may be disturbed by human activities. A non-technical definition of the SPL is the instantaneous level of sound received. NOAA typically considers a received $\mathrm{rms}$ SPL $\geq 180 \mathrm{~dB}$ as the threshold above which cetaceans may be injured physically. Southall et al. (2007) suggested that these rms SPL-based injury thresholds are not supported by empirical data on the physical effects of sound. They further suggested that cetaceans with sensitivity to low-frequency sounds (e.g. baleen whales) may receive an auditory injury from impulsive sounds with peak SPL $\geq 230 \mathrm{~dB}$ or cumulative sound exposure levels (SEL; in $\mathrm{dB}$ re $1 \mu \mathrm{Pa}^{2} \mathrm{~s}$, accumulated over $24 \mathrm{~h}$ ) >198 dB, and by non-pulse sounds with cumulative SEL $\geq 215 \mathrm{~dB}$ (Southall et al. 2007). The SEL is an integrative measure of the received SPL over a given period of time, e.g. $24 \mathrm{~h}$.

The nature and methods of calculating SPL versus cumulative SEL are fundamentally different. However, in most regulatory assessments in the U.S., both SPL and cumulative SEL are treated as static thresholds for the onset of injury or behavioral effects. Data are rarely sufficient to consider dynamic interactions 
among an animal, the sound field to which it is exposed at a particular time and place, and the biology of the animal (e.g. its identity, age, sex, and condition). Recent workshops and forums have considered potential methods for estimating the cumulative effects of anthropogenic underwater sound that are more informative than simple thresholds of take (i.e. a single specified level of sound that indicates potential injury or harassment; NOAA 2012). The individualbased Acoustic Integration Model ${ }^{\circledR}$ (AIM) (Frankel et al. 2002, Independent System for Peer Review 2006) that we used in this study can evaluate complex cumulative SELs. To date, the AIM has been applied to inform diverse major environmental studies and environmental impact statements that examined potential responses of marine mammals to multiple sources of sound, such as shipping, airguns, and sonar (e.g. Department of the Navy 2001, Gabriele et al. 2010, NSF-USGS 2011).

Clark et al. (2009) examined potential effects on endangered baleen whales of the aggregated sound field generated by one or more commercial ships. They used the aggregated sound field to measure the potential effect of a reduction in communication space, referred to as communication masking. Hatch et al. (2012) calculated communication-masking metrics to evaluate the aggregated effects of sound from 117 commercial ships on a modeled population of 89 North Atlantic right whales Eubalaena glacialis off Boston, Massachusetts, over 1 mo. Clark et al. (2009) calculated measures of communication masking for individual modeled whales, whereas Hatch et al. (2012) calculated masking at the level of the group of simulated whales. We built on those previous methods of assessment by quantifying the aggregated contributions to exposure from multiple sources of underwater sound, both continuous and impulsive, associated with the offshore oil and gas industry.

The US National Environmental Policy Act (NEPA) is generally interpreted to require an analysis of 'the impact on the environment which results from the incremental impact of the action when added to other past, present, and reasonably foreseeable future actions' (40 CFR $\S \S ~ 1500-1508$; Council on Environmental Quality 1997). An analysis of the cumulative effects of human activities ideally would encompass the effects not only of sound, but of all potential stressors. Nevertheless, developing a quantitative process to estimate exposure to multiple sound sources could enhance cumulative-effects analyses.

Our objective was to develop a quantitative method for estimating the sound exposure level of marine mammals to multiple sources of continuous and impulsive anthropogenic sound over weeks to months, and, as a proof of concept, to apply this method to a simulated population of marine mammals. Some species of marine mammals, such as gray whales, have been observed avoiding sound sources in their migratory path (Malme et al. 1984, Buck \& Tyack 2000, Ellison et al. 2012). Therefore, we aimed to conduct an initial exploration of how changes in movement paths of modeled animals programmed to avoid certain received levels of sound (i.e. aversion) might affect both sound exposure and travel distance.

\section{METHODS}

To develop the modeling method and our simulations, we focused on bowhead whales Balaena mysticetus in the Alaskan Beaufort Sea. Bowhead whales have cultural meaning for Alaska natives, and subsistence hunting of the species is protected under the MMPA. The species is also listed as endangered under the US Endangered Species Act. Each autumn, bowhead whales move westward from feeding areas in the Canadian Beaufort Sea through the Alaskan Beaufort Sea and into the Chukchi Sea. This region increasingly is a focus of exploration for and production of oil and gas. We bounded our model in space from about $144-152^{\circ} \mathrm{W}$ and in time from 1 September through 23 October 2008. These extents encompass most of the autumn migration through the region. We selected 2008 because it was a year of relatively high intensity of seismic exploration in the region (Roth et al. 2012).

As detailed below, we first modeled the sound field generated by each anthropogenic sound source during a defined period of time. Second, we simulated the movements of migrating whales through each of these sound fields. We refer to the simulated whales as animats. Each animat functions as an acoustic dosimeter that records its exposure at $30 \mathrm{~s}$ intervals. In 1 run of the simulation model, we assumed that the animats would not or could not change their movement path to avoid a given received level of sound (i.e. would not or could not avert). In another model run, we allowed the animats to avert from certain received sound levels. Third, we recorded the modeled SPL rms history and then calculated the resulting cumulative SEL for each animat from each source. Fourth, we estimated the aggregated exposure from all sources for each modeled whale. Individual animats migrated through the sound fields in 3-4 d. The entire modeled population moved through the area over $47 \mathrm{~d}$. 


\section{Acoustic modeling}

We compiled data on sounds from oil and gas production, seismic exploration, and vessel traffic from publicly available sources. These sources included a multi-year comprehensive report (Funk et al. 2010), applications for incidental harassment authorizations under the MMPA, and post-exploration season monitoring reports (www.nmfs.noaa. gov/pr/permits/incidental.htm\#applications). On the basis of these empirical data, we modeled the sound fields generated by the Northstar and Oooguruk production islands, 1 offshore and 1 nearshore vessel towing a barge ('barge tow'), and 2 offshore and 3 nearshore seismic survey operations (Fig. 1). The production islands and barge

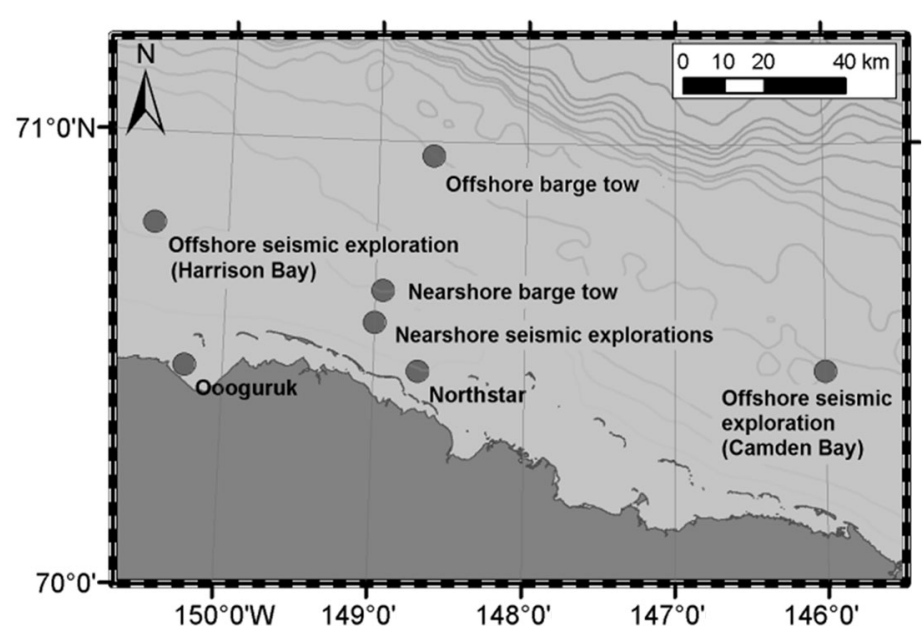

Fig. 1. Locations of sound-producing operations included in the model of the aggregated anthropogenic sound field in the Alaskan Beaufort Sea. Oooguruk and Northstar are production islands. The darker grey toward the south indicates mainland Alaska. Contour lines are in $10 \mathrm{~m}$ increments tows produced sound throughout the assessment period, whereas seismic exploration was episodic and varied among operations (Table 1).

Our intent was not to recreate the precise temporal, spectral, and spatial properties of the anthropogenic sound field but to generate a plausible aggregated sound field. We kept the acoustic model relatively simple and tractable by selecting sources of sound that represented different major classes of activities, including those with the strongest outputs of sound. We further prioritized simplicity and tractability of the acoustic model by assuming that all sound sources were stationary. These simplifications precluded a quantitative estimate or validation of true sound exposure in the region during the simulated period. However, they allowed for realistic, transferable modeling of a dynamic, anthropogenic sound field in which the moving animats were exposed to received sound levels greater than nominal ambient sound, which we considered to be a biologically meaningful scenario.

We estimated 3 acoustic metrics: rms SPL, perimpulse SEL (in $\mathrm{dB}$ re $1 \mathrm{\mu Pa}^{2} \mathrm{~s}$ ), and cumulative SEL (see Southall et al. 2007, their Appendix A). We based cumulative SEL on the aggregated exposure of each animat to all sound sources for the duration of its exposure period (e.g. Madsen 2005, Madsen et al. 2006). Estimates of aggregated exposure are dominated by the source producing the highest received level, which typically occurs when the receiver is at or near its closest point of approach to the sound source.

Southall et al. (2007) proposed new criteria for sound exposure that were based on M-weighted SEL (i.e. sound exposure levels adjusted to the hearing curve of a hypothetical marine mammal). We instead used unweighted values of SEL (i.e. measures of sound not adjusted to a hearing curve) to

Table 1. Major anthropogenic sources of sound in the Alaskan Beaufort Sea during the autumn bowhead whale (Balaena mysticetus) migration in 2008 (1 September-23 October). 1 inch $^{3} \approx 16.39 \mathrm{~cm}^{3}$

\begin{tabular}{|lll|}
\hline Activity & Dates of activity & Characterization of activity \\
\hline Northstar production island & 1 Sep-23 Oct & Routine production with vessel support \\
Construction of Oooguruk production island & 1 Sep-23 Oct & Construction with vessel support \\
Offshore barge tow & 1 Sep-23 Oct & Generic barge tow typical of Beaufort Sea \\
Nearshore barge tow & 1 Sep-23 Oct & Generic barge tow typical of Beaufort Sea \\
Offshore seismic exploration in Harrison Bay & 3-12 Sep and 1-9 Oct & $\sim 3000$ inch $^{3}$ airgun array \\
Offshore seismic exploration in Camden Bay & 14-29 Sep & $\sim 3000$ inch $^{3}$ airgun array \\
Nearshore seismic exploration 1 & 3-5 and 20-28 Sep & $\sim 900$ inch $^{3}$ airgun array \\
Nearshore seismic exploration 2 & 1-28 Sep & $\sim 900$ inch $^{3}$ airgun array \\
Nearshore seismic exploration 3 & 6-13 Sep & $\sim 450$ inch $^{3}$ airgun array \\
\hline
\end{tabular}


calculate cumulative exposures. Use of unweighted values tends to result in higher estimated levels of exposure than use of weighted values, and therefore is likely to be considered by regulators as a more conservative method. On the basis of data on hearing in cetaceans, the most recent draft guidelines for low-frequency weighting (NOAA 2013) proposed modifications to the M-weighting curve, but these modifications have not been validated for general application.

We assumed that during a given $24 \mathrm{~h}$ period, each of the airgun arrays used in seismic surveys could be either inactive (silent) or constantly active and firing at $10 \mathrm{~s}$ intervals with a $100 \mathrm{~ms}$ impulse duration. For these impulsive sources, we modeled the perimpulse SEL and assumed a nominal impulse duration across the sound field of $100 \mathrm{~ms}$ (Richardson et al. 1995a) regardless of the distance from the source, with no acoustic energy in the periods between impulses. We calculated rms SPL values as SPL $=$ SEL - $10 \log _{10}$ (impulse duration in seconds); for a $100 \mathrm{~ms}$ impulse, the SPL is SEL + $10 \mathrm{~dB}$. Acoustic measurements taken in the highly reverberant shallow waters of the North Slope of Alaska (Guerra et al. 2011) do not support the assumption that pulse dispersion and multipath propagation are functions of range from the source. However, the net result of the simplified relation we used to calculate SPL is an overestimation of rms SPL as distance from the seismic source increases.

We estimated the source levels (per-impulse SEL in 1/3-octave bands) for the airgun arrays used in the seismic surveys (Table 1) on the basis of a full-waveform airgun array source signature model (AASM; MacGillivray 2006). This model is based on the oscillation and radiation of air bubbles released as airguns discharge (Ziolkowski 1970). The model accounts for pressure interaction between bubbles, effects of reflection from the water's surface on pressure, heat transfer from bubbles to the surrounding water, and buoyancy of the bubbles.

We estimated source levels for barge tows and production islands on the basis of underwater measurements from these and comparable activities (e.g. Blackwell et al. 2004). For the barge tow, we used a single, ocean-bound tug in cruise transit mode as the representative source; we obtained its 1/3octave band source levels from an extensive collection of sound source measurements (Hannay et al. 2004). We assumed that support vessels operating in proximity of production islands would generate the highest levels of sound, and we obtained representative 1/3-octave band source levels for a shallow- draft utility and crew-transfer vessel transiting at low speed from Hannay et al. (2004). The broadband rms source level (10-1000 Hz) of this vessel was set at $172 \mathrm{~dB}$ re $1 \mu \mathrm{Pa} @ 1 \mathrm{~m}$ (Hannay et al. 2004).

We obtained basin-level bathymetry data from the Geographic Information Network of Alaska (GINA) online database (Lindquist et al. 2004). We derived sound velocity profile curves from the Generalized Digital Environmental Model Variable Resolution (GDEM-V) database published by the US Naval Oceanographic Office (Teague et al. 1990). Given the seabed composition of the regions where the sources were located, we used 2 sets of geo-acoustic parameters in the models: one for Harrison Bay and adjacent regions to the east, where some of the sound-producing activities were located, and one for Camden Bay (Fig. 1). We derived the parameters from the geological properties of the seafloor strata with the method of Hamilton (1980).

We used the Marine Operations Noise Model (MONM) (Hannay \& Racca 2005) to estimate the sound field produced by individual sources. This model computes acoustic-transmission loss in individual frequency bands and solves the acoustic wave equation as a parabolic function as implemented in the US Naval Research Laboratory's Range-dependent Acoustic Model (RAM) (Collins 1993). The MONM uses a complex density approximation (Zhang \& Tindle 1995) to account for reductions in water-borne sound caused by transfer of energy from the water column to the seabed in the form of shear waves. We estimated 3-dimensional acoustic propagation over an extensive region by modeling transmission loss in 1/3-octave bands from 10 to $1000 \mathrm{~Hz}$ center frequency along a fan of 2-dimensional radial grids at uniform angular increments, each grid evenly spaced in depth and range from the source. Most of the sound intensity for the sources modeled is concentrated in this frequency band. We applied the calculated frequencydependent transmission loss to the estimated source levels in corresponding bands. For each sound source, we computed the resulting broadband sound levels $(10-1000 \mathrm{~Hz})$ on a uniform grid of points over the modeled geographic region of interest. For each of the 7 weeks during the modeled time period, we computed the aggregated received sound level at each animat by summing the received sound energy from each source. Different sources operated each week, and their locations varied (Fig. 2). 

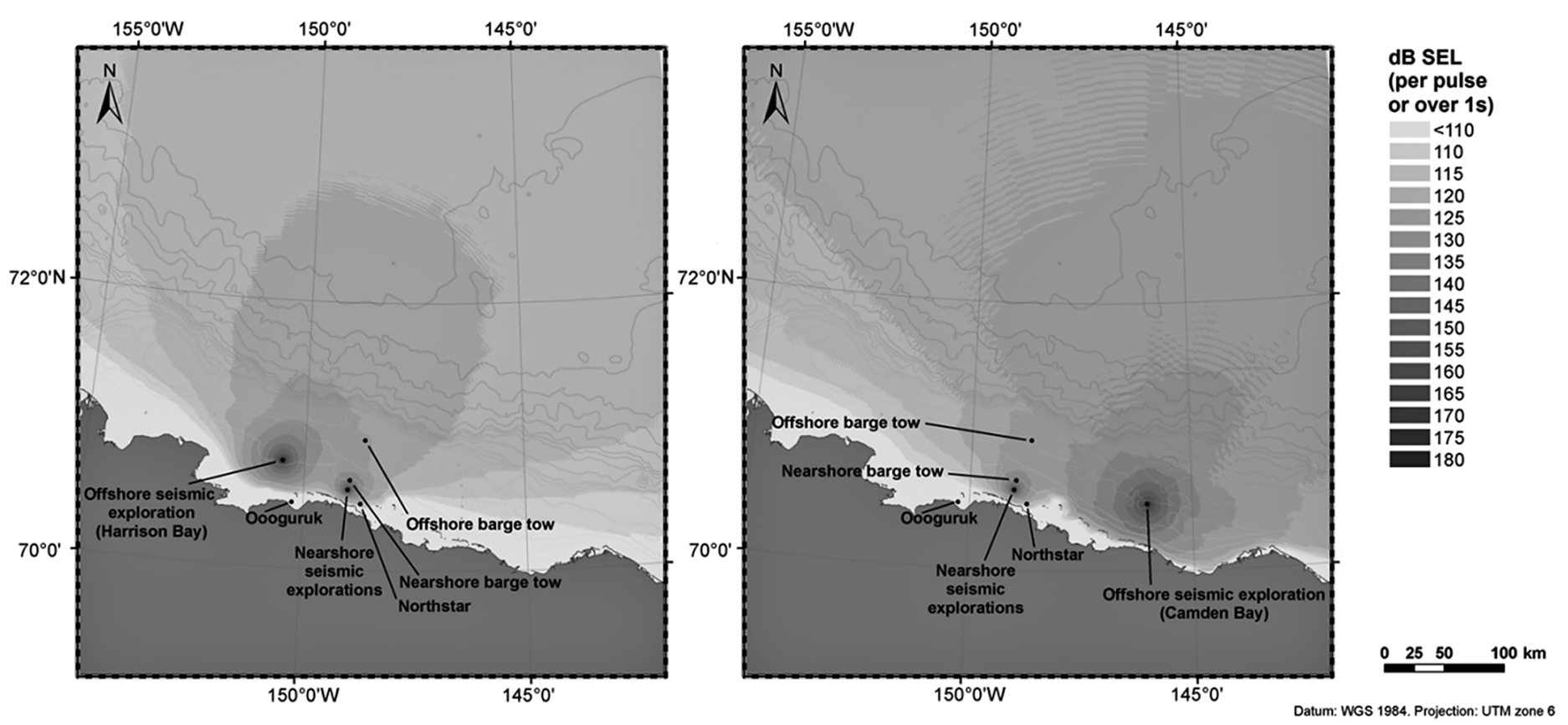

Fig. 2. Two examples of the aggregated acoustic environment (maximum level of sound over the full water column) for periods during which 5 sound sources were operating in the Alaskan Beaufort Sea (left panel, 3-5 September; right panel, 20-28 September). SEL: sound exposure level. For further details see Fig. 1

\section{Modeling movements and exposures}

We used the Acoustic Integration Model ${ }^{\circledR}$ (Frankel et al. 2002), a Monte Carlo-based statistical model, to simulate movements of bowhead whales through each of the aggregated sound fields and to calculate each modeled whale's exposure over time. The AIM is based in part on a model of whale movement and tracking developed for acoustic censuses of bowhead whales (Ellison et al. 1987b).

The parameters in our model of bowhead whale movement and exposure were the local population size for each week during the modeled time period, percentage of the population in the Alaskan Beaufort Sea throughout the migration period, distance of individual animats from the coastline, direction and speed of motion, dive time and dive depth, surface time, water depth, sound exposure level, and aversion or no aversion to sound. Empirical data are limited, but we felt they were sufficient to estimate these parameters as a proof of concept of the method. We did not aim to assess the goodness-of-fit between the outputs of our simulations and field observations.

We extrapolated the size of the bowhead whale population migrating westward in 2008 (14 400) from the estimated population size (10 470) and population growth rate (3.4\%) in 2001 (George et al. 2004). On the basis of traditional and scientific observations in the local region, we estimated that $80 \%$ of the popu- lation migrated through the Alaskan Beaufort Sea between 1 September and 12 October. Therefore, the population size for our simulations was 11566 . For each modeled week, we designated a percentage of the population as migrating (Table 2).

Aerial survey data suggested that the density distribution of bowhead whales is a function of water depth and distance offshore (Clarke \& Ferguson 2010), with approximately $95 \%$ of the animals in the nearshore region (depths of $20-200 \mathrm{~m}$ ) and $5 \%$ in the offshore region (depths of 50-2000 m). Therefore, we modeled bowhead whales in the nearshore and off-

Table 2. Dates within each modeled period, number of animats (simulated whales) traveling nearshore $(20-200 \mathrm{~m}$ water depth) or offshore (50-2000 m water depth) during each period, and percentage of each group (in parentheses) migrating during each period. Modeled animats were placed throughout the $144-152^{\circ} \mathrm{W}$ area. New animats entered the simulation from the east as the westernmost animats swam out of the modeled area to the west

\begin{tabular}{|lcc|}
\hline Modeled period & Nearshore & Offshore \\
\hline 1-7 Sep & $2198(21)$ & $119(20)$ \\
8-13 Sep & $2352(21)$ & $126(21)$ \\
14-19 Sep & $2352(21)$ & $126(22)$ \\
20-26 Sep & $1959(18)$ & $102(17)$ \\
27 Sep-2 Oct & $1098(10)$ & $56(10)$ \\
3-9 Oct & $671(6)$ & $36(6)$ \\
10-16 Oct & $350(3)$ & $21(4)$ \\
\hline
\end{tabular}


shore regions separately, allowing some overlap of the 2 regions at depths of $50-200 \mathrm{~m}$.

We populated each simulation with westwardmigrating animats (i.e. animats east of $144^{\circ} \mathrm{W}$ that moved into the modeled area over time) at the beginning of each 1 wk period. A week is long enough for a westward migrating bowhead whale to traverse the modeled portion of the Alaskan Beaufort Sea.

We assumed that animats began their migration on a generally westerly heading. We allowed each animat's heading to change randomly by $\leq 10^{\circ}$ every 5 min, always maintaining an attraction to the west, but confining the travel path to the allocated depth contours for the nearshore and offshore distributions (i.e. following the contour of the coast). We allowed the speed of each animat to vary from 4 to $6 \mathrm{~km} \mathrm{~h}^{-1}$ on the basis of limited data from satellite tags deployed by Mate et al. (2000). The tags recorded a mean speed of $3.8 \mathrm{~km} \mathrm{~h}^{-1}$ among 8 bowhead whales that were either feeding or migrating, with individual mean speeds of $1.1-5.8 \mathrm{~km} \mathrm{~h}^{-1}$. One of the tagged bowhead whales (DZ-1) was tracked along its full migration route from Canada to Russia. The mean speed of this whale was $5.0 \mathrm{~km} \mathrm{~h}^{-1}$. Because calculations of distances between locations assumed straight-line travel, and therefore represent the minimum distance and speed, the speeds reported by Mate et al. (2000) probably underestimated true speeds.

On the basis of satellite tag data, we modeled both the duration and depths of 2 types of dives: relatively short, shallow dives and relatively long, deep dives. Bowhead whales tagged by Krutzikowsky \& Mate (2000) spent $60 \%$ of their time diving at depths $<16 \mathrm{~m}, 33 \%$ of their time at depths from 17 to $96 \mathrm{~m}$, and $<3 \%$ of their time at depths $>96 \mathrm{~m}$, with a maximum dive depth of $352 \mathrm{~m}$ (water depth permitting); they spent a mean of $5.5 \%$ of their time at or near the surface. We assigned $60 \%$ of the nearshore and offshore animals to the short, shallow dive type, with $5-16 \mathrm{~m}$ dive depths in both regions, and $40 \%$ to the long, deep dive type. Because water depth decreases as distance from the shoreline decreases, we assumed that depths of the longer, deeper dives of nearshore bowhead whales ranged from 17 to $50 \mathrm{~m}$ and those of offshore bowhead whales ranged from 17 to $96 \mathrm{~m}$. The satellite tag data also showed that the durations of dives $>1$ min were 2.6-30.4 min, independent of dive depth, with individual means from 6.9 to $14.1 \mathrm{~min}$ and an ensemble mean of $10.4 \mathrm{~min}$. However, when ice cover was $<90 \%$, the majority of dives were $\leq 13 \mathrm{~min}$, with a relatively small percentage of longer dives (Fig. 7a in Krutzikowsky \& Mate
2000). Because duration and dive depth were independent, we selected durations of 3-10 min for the shorter dives and 8-13 $\mathrm{min}$ for the longer dives. These dive durations are consistent with those reported earlier (Dorsey et al. 1989, Richardson et al. 1995b).

As described in the previous subsection, we modeled the exposure of the animats to sound during 7 wk (Table 2), corresponding approximately to the onset and completion of the population's migration period (Table 1). We used the AIM to estimate the instantaneous level of sound (continuous or impulse rms SPL, depending on the source type) received by the animat from each source at $30 \mathrm{~s}$ intervals as it migrated westward through the Alaskan Beaufort Sea. In essence, the model created an aggregated acoustic dosimeter record at $30 \mathrm{~s}$ increments for each animat.

To illustrate the exposure-modeling process, we calculated the exposure over a $78 \mathrm{~h}$ period (the approximate duration of one animal's migration through the Alaskan Beaufort Sea) for a single inshore migrating animat that passed close to both offshore and nearshore seismic operations, the Northstar production island, and one of the barge tows. We used these results to calculate both the maximum SPL and the cumulative SEL for each animat. We compared our modeled estimates of the aggregated received sound levels to the potential range of sound levels to which a marine mammal in this region might be exposed in the absence of anthropogenic sound. To estimate the latter range, we used empirical measurements of non-impulsive ambient sound levels for September 2008 at a location on the shelf slope near the border between the Chukchi and Beaufort Seas (Roth et al. 2012). The Roth et al. (2012) data present broadband $(10-1000 \mathrm{~Hz})$ values of $96 \mathrm{~dB}$ re $1 \mu \mathrm{Pa}^{2}$ for the $10^{\text {th }}$ percentile and $117 \mathrm{~dB}$ re $1 \mathrm{\mu Pa}^{2}$ for the $90^{\text {th }}$ percentile; these values are higher than those provided in earlier assessments for this region (Urick 1983, Richardson 1995a). Because Roth et al. (2012) monitored sound at a depth of $235 \mathrm{~m}$ in a location exposed to sound propagated from full ocean depth, their reported ambient levels potentially could be higher than in the shallow water of the inshore migrating animats.

We ran 2 separate sets of AIM simulations, one in which the whales in the simulated population could not change their movement path to avoid certain sound levels (i.e. avert) and one in which they could avert. In the simulations that did not allow aversion, animats were not programmed to respond to the 
sound exposure level, and as a result their migration paths were unaffected by the modeled sound sources. In the second set of simulations, animats were programmed to avert from a sound source as a function of their acoustic environment. The 4 parameters in the aversion function were the SPL threshold at which an animat was assumed to respond, the probability that the animat would respond, the aversion response angle, and the rate at which the animat subsequently evaluated the sound field (SPL) (Table 3). Our selection of aversion parameters for bowhead whales was intended to represent a reasonably expected behavioral response to sound exposure, not to predict response behavior explicitly.

Of the 4 parameters, probability of aversion had the greatest effect on the behavioral response, and aversion would be the most tractable to validate in the field. Although we set the probability of aversion at SPL $\geq 160 \mathrm{~dB}$ re $1 \mu \mathrm{Pa}$ at 0.60 , the sound level at the animat was reevaluated every $5 \mathrm{~min}$. Accordingly, an animat that continued toward the sound source and did not avert at the first level eventually would be

Table 3. Aversion parameters for animats (simulated whales) used in models of movement and sound exposure. rms: root mean square; SPL: sound pressure level

\begin{tabular}{|lccc|}
$\begin{array}{l}\text { Received SPL } \\
\text { threshold }(\mathrm{rms} \\
\text { SPL, dB re } 1 \mu \mathrm{Pa})\end{array}$ & $\begin{array}{l}\text { Probability } \\
\text { of aversion }\end{array}$ & $\begin{array}{c}\text { Aversion } \\
\text { angle }\left(^{\circ}\right)\end{array}$ & $\begin{array}{c}\text { Interval } \\
\text { between SPL } \\
\text { evaluations (s) }\end{array}$ \\
\hline$\geq 160$ & 0.60 & 10 & 300 \\
$\geq 170$ & 0.85 & 20 & 60 \\
$\geq 180$ & 0.99 & 30 & 30 \\
\hline
\end{tabular}

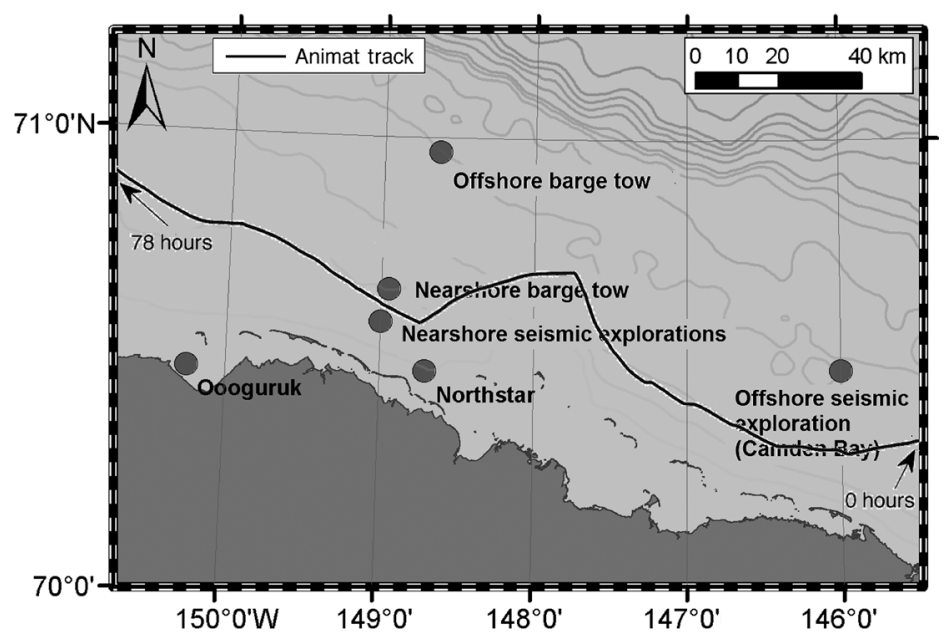

Fig. 3. Example of an animat (simulated whale) track over the $78 \mathrm{~h}$ period of its migration through the Alaskan Beaufort Sea (without aversion). For further details see Fig. 1 exposed to SPL $\geq 160 \mathrm{~dB}$ re $1 \mu \mathrm{Pa}$ and again would have the opportunity to avert. We acknowledge that bowhead whales may respond to received impulsive and continuous sound at SPL $<120 \mathrm{~dB}$ re $1 \mu \mathrm{Pa}$ (Richardson et al. 1995a, Davies 1997, Richardson 1999, McDonald et al. 2012). However, we limited aversion responses to received SPL $\geq 160 \mathrm{~dB}$ re $1 \mu \mathrm{Pa}$ to allow the animats to move through the sound field and to run the model more efficiently. Again, our intent was not to yield outputs that fit field observations, but to develop a transferable method that can be parameterized with data on different activities, locations, and species.

We summarized the exposure for all animats in the modeled populations. We used the single maximum received SPL value for each animat, regardless of source type, as data for both of the aversion options. We binned values in $5 \mathrm{~dB}$ increments from 120 to $220 \mathrm{~dB}$ re $1 \mu \mathrm{Pa}$. We calculated the corresponding distribution of cumulative SEL values, computed for each animat by summing the sound exposures from all active sources over all time steps in a run.

\section{RESULTS}

\section{Example of individual-level exposure}

A single inshore migrating animat (not programmed to change its movements in response to a given sound level) selected from the migrating population illustrates exposure to multiple sources as the animat traveled close to both offshore and nearshore seismic operations, the Northstar production island, and one of the barge tows (Fig. 3) over $78 \mathrm{~h}$. In this case, the large offshore seismic array was the dominant contributor to received sound levels throughout the animat's entire passage, except from about $32-41 \mathrm{~h}$ after the simulated migration began (Fig. 4). During those $9 \mathrm{~h}$, the animat passed in close proximity to the nearshore seismic operation, which then dominated the received sound level. The animat's closest point of approach to the offshore seismic source was about $25 \mathrm{~km}$, and occurred about $5 \mathrm{~h}$ after the simulation began. The SPL at that point was about $150 \mathrm{~dB}$ re $1 \mu \mathrm{Pa}$. The received SPLs from individual pulses from the offshore seismic source were $>120 \mathrm{~dB}$ re $1 \mu \mathrm{Pa}$ throughout the animat's migration. The animat reached its closest range of approach to the nearshore seismic operation - a few kilometers - approximately $36 \mathrm{~h}$ after its simulated migration began, and the received SPL of impulses from the nearshore seismic operation peaked at just above 


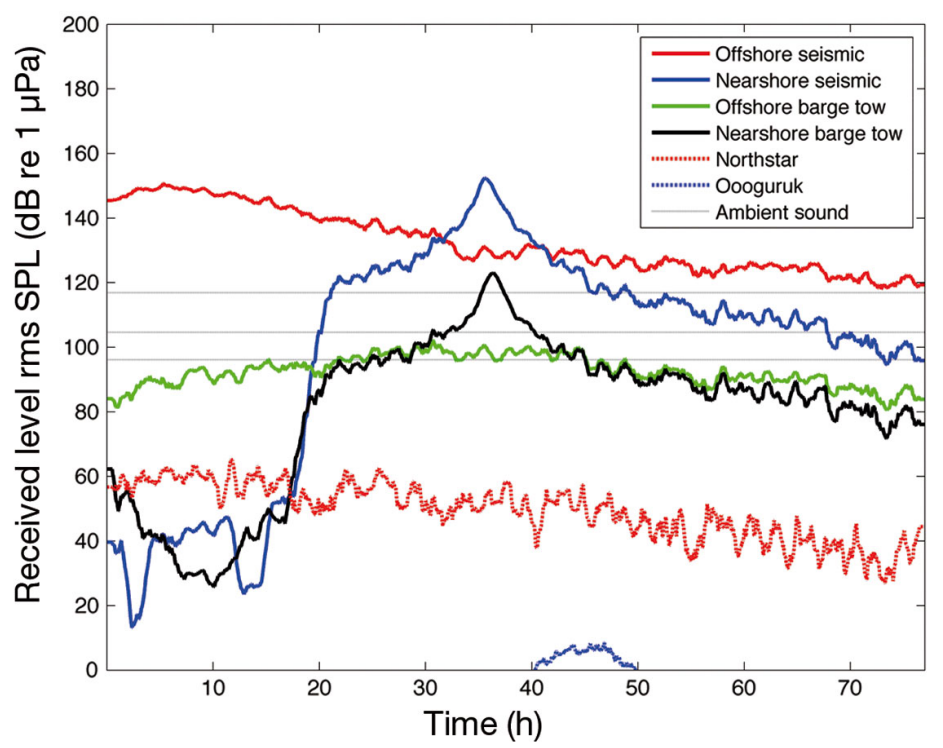

Fig. 4. Instantaneous levels of sound (broadband continuous or impulse root mean square sound pressure level [rms SPL]) received from each source at $30 \mathrm{~s}$ intervals by the animat (simulated whale) represented in Fig. 3. Gray horizontal lines denote the median and upper $(90 \%)$ and lower $(10 \%)$ bounds of broadband (10-1000 Hz) ambient sound (Roth et al. 2012)

$150 \mathrm{~dB}$ re $1 \mu \mathrm{Pa}$. The maximum received SPL levels were about $45 \mathrm{~dB}$ higher than the mean ambient band level $(10-1000 \mathrm{~Hz})$ estimated by Roth et al. (2012).

The next-highest received SPL values occurred during the animat's closest approach to the nearshore barge tow as the animat passed between the barge tow and the nearshore seismic source. At this point, the received sound level at the animat reached a maximum SPL for both the nearshore seismic operation $(150 \mathrm{~dB}$ re $1 \mu \mathrm{Pa}$ ) and the nearshore barge tow ( $125 \mathrm{~dB}$ re 1 $\mu \mathrm{Pa})$, the latter at a closest point of approach of $2.4 \mathrm{~km}$. Although the continuous sound exposure from the barge tow for this animat never exceeded the impulse SPL from either of the seismic sources, the level of sound from the barge tow was the highest that reached the animat in the short intervals between airgun impulses. During the $78^{\text {th }}$ hour of this animat's transit, it was exposed to sound levels from some combination of the seismic sources above the $90^{\text {th }}$ percentile ambient in the $10-1000 \mathrm{~Hz}$ band (Roth et al. 2012). With respect to the SPL levels from the continuous sources, only those from the 2 barge tows exceeded the $10^{\text {th }}$ percentile ambient levels, and the levels in the same band from the production activities at
Northstar and Oooguruk were well below the $10^{\text {th }}$ percentile ambient. For $83 \%$ of the $78 \mathrm{~h}$ migration period, the animat received sound levels that were $>20 \mathrm{~dB}$ re $1 \mu \mathrm{Pa}$ greater than the estimated mean ambient in the $10-1000 \mathrm{~Hz}$ band (Roth et al. 2012). These insights would not be evident from traditional reports of a single peak measurement.

\section{Population-level exposure}

The proportion of the simulated population that was exposed to SPL $>165 \mathrm{~dB}$ re $1 \mu \mathrm{Pa}$ decreased markedly when the animats were allowed to avert (Fig. 5a). However, some animats in the population that could avert were still exposed to SPL $>165 \mathrm{~dB}$ re $1 \mu \mathrm{Pa}$, probably because they had a finite probability of not averting at each time step and because new sound sources were activated during the migration. The cumulative SEL was considerably lower for a population of animats that could avert than for a population of animats that could not avert (Fig. 5).

We calculated the percentage of animats in each modeled population that were exposed to a range of maximum SPLs (Fig. 6). For example, about $6 \%$ of the animats in the population that could not avert
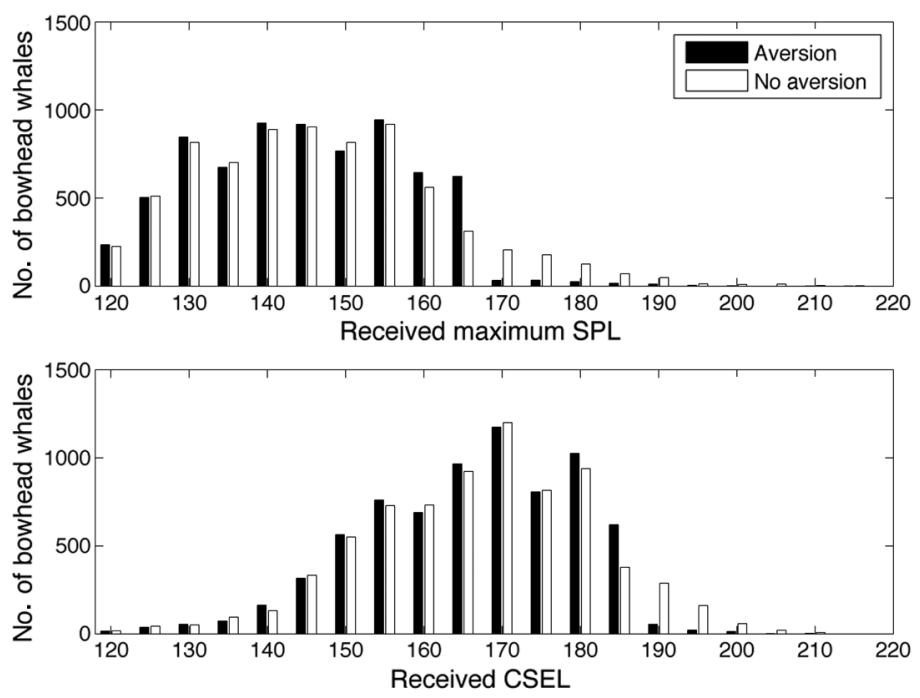

Fig. 5. Aggregated maximum received sound pressure levels (rms SPL; in $\mathrm{dB}$ re $1 \mu \mathrm{Pa}$ ) (upper panel) and cumulative sound exposure levels (CSEL; in $\mathrm{dB}$ re $1 \mu \mathrm{Pa}^{2} \mathrm{~s}$ ) (lower panel) for all animats (simulated whales) during their autumn migration through the Alaskan Beaufort Sea. The CSEL for each animat is the sum of its exposure to sound from all sources over all time steps 


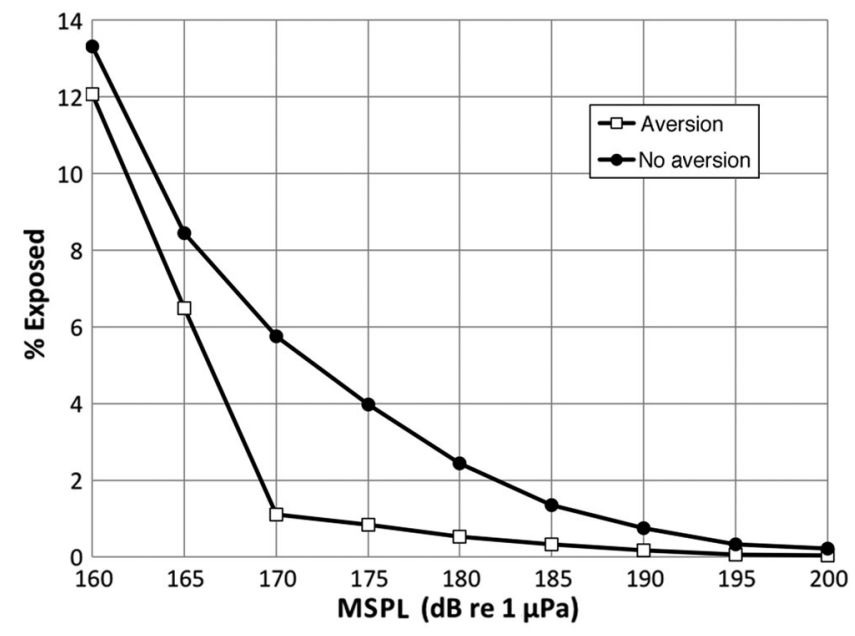

Fig. 6. Percentage of animats (simulated whales) in the population that were exposed to maximum sound pressure levels (MSPL) equal to or greater than given values as a function of whether they averted from those levels

were exposed to SPL $\geq 170 \mathrm{~dB}$ re $1 \mu \mathrm{Pa}$. By contrast, about $1 \%$ of the animats in the population that could avert were exposed to $\mathrm{SPL} \geq 170 \mathrm{~dB}$ re $1 \mu \mathrm{Pa}$.

In our models, aversion from any sound source had little effect on travel distance. For example, between 145.5 and $146.5^{\circ} \mathrm{W}$, where a seismic operation was positioned, the average distance traveled by animats in the population that could not avert from rms sound levels of $\geq 160 \mathrm{~dB}$ re $1 \mu \mathrm{Pa}$ was $41 \pm 14 \mathrm{~km}$ (mean \pm $\mathrm{SD})$. The average distance traveled by animats in the population that could avert was $46 \pm 19 \mathrm{~km}$. When we assessed sound exposure along the full migration path (Fig. 1), we found the difference in mean total distance swum by either population was $<1 \mathrm{~km}$. This result is consistent with the fact that the $160 \mathrm{~dB}$ SPL threshold for the onset of aversion occurred at a nominal range of $10 \mathrm{~km}$ from the largest airgun array. Each animat encountered a large array once during the $78 \mathrm{~h}$ mean duration of passage, and only animats that passed within $10 \mathrm{~km}$ of an active large array had the potential to avert. Overall, approximately $5 \%$ of individuals in the population that could avert changed their movement paths.

\section{DISCUSSION}

Our approach differed in 2 ways from conventional acoustic impact assessment analyses. First, we estimated both SPL and cumulative SEL for each migrating animat as it moved through a temporal series of representative, static, aggregated sound fields generated by multiple sources, including ves- sels and seismic airguns. Second, one of our 2 model runs included the potential for an animat to avert from a sound source with a probability proportional to the received SPL. Altering the aversion parameters could result in substantial changes in the modeled results, especially if the SPLs at which animats averted were reduced. As a result, a higher proportion of animats would be exposed to lower levels of sound. To illustrate, if the $160 \mathrm{~dB}$ threshold was lowered to $155 \mathrm{~dB}$ and the probability of aversion was set to $50 \%$, then approximately $50 \%$ of the animats previously exposed to 155-160 dB would be exposed to $<155 \mathrm{~dB}$. The use of aversion as a modeling method emphasizes the need for more-extensive empirical data on avoidance behaviors. For example, additional sensitivity analyses of our stochastic aversion approach might inform prioritization of empirical data collection on bowhead whales' aversion responses. Such data might be similar to those of Thompson et al. (2013), who used detections of foraging-related sounds to demonstrate sound-level proportional a version by harbor porpoise Phocoena phocoena to airgun activity over an extent similar to that of our case study.

Understanding the effects of sound exposure will be improved by analyzing dynamic interactions between animals and sound fields or biological variables that affect how animals respond to exposure (Ellison et al. 2012). On the basis of our results, we emphasize the potential increase in information that can be gained not only by modeling the spatial and spectral variability in the sound field produced by multiple sources, but also by broadening the assessment to explicitly quantify the time-varying dynamics of the interaction between animals and the acoustic environment over ecologically meaningful durations.

Extended periods of chronic exposure to impulsive sound at levels above ambient, but $<160 \mathrm{~dB}$ re $1 \mu \mathrm{Pa}$ $\mathrm{SPL}$, are not considered in current assessments of regulatory take, although exposures to continuous sounds $>120 \mathrm{~dB}$ re $1 \mu \mathrm{Pa}$ SPL are considered as regulatory takes. Measures of exposure such as signalto-noise ratio, sensation level, or perceived sound level are not typically addressed in environmental studies, although they are now recognized as biologically relevant to both behavioral responses and chronic effects of sound (Ellison et al. 2012). Chronic exposure at levels substantially above ambient may inform spatial planning, and is likely to have some effect on bowhead whales and other species of whales, perhaps by masking of acoustic communication signals or navigational cues (Ellison et al. 1987a, 
George et al. 1989, Clark \& Ellison 2004, Clark et al. 2009, Hatch et al. 2012).

Our model treated impulsive and continuous sounds in the same way - that is, by estimating the maximum level in every $30 \mathrm{~s}$ interval. In reality, sounds from seismic airgun arrays are sequential discrete impulses, with a single array producing an impulse at intervals of about 8 to $15 \mathrm{~s}$. Continuous sources, if present and included in the aggregate sound level, maintain elevated sound levels during the interstitial periods between impulses. Furthermore, the timing of the impulse from the large and the small seismic sources may be staggered, so sound is generated between each source's impulses. Propagation of acoustic energy from impulsive sources also raises sound levels between seismic impulses through boundary reverberation and multipath propagation effects (Guerra et al. 2011). Thus, sounds originating from a single source potentially arrive at a receiver via different pathways and at different times. Reverberation from the ocean floor near airgun activity may be substantially above ambient sound levels in extremely shallow nearshore environments such as those we modeled, and reverberation and ambient sound levels may be elevated further when multiple seismic operations are being conducted in the same region. Although increases in sound levels between impulses typically are below current regulatory thresholds, they raise background levels and potentially could hinder the ability of animals to communicate or to acoustically sense their environment.

\section{Biological effects of aversion}

The tendency of bowhead whales to avert from areas in which industrial sound sources operate was noted by Richardson et al. $(1985,1995 \mathrm{a})$ and in numerous reports (see Schick \& Urban 2000). Although it is logical to assume that animals averting from sound sources swim greater distances than those that do not, the extent to which aversion affects the overall migration distance or duration of migration is unknown. Additionally, the biological effects of increased migration distances are not known. Our analysis was essentially a parametric exploration of the possible movement response of bowhead whales to a given sound level. Our estimated input parameter values of aversion behavior were bounded by 160 and $180 \mathrm{~dB}$ re $1 \mu \mathrm{Pa}$ SPL, the long-established NOAA assumptions of levels that affect behavior and cause injury. This range of reference values thus is well-understood by industry, researchers, and regulators. More substantive estimates, particularly for initial aversion that might occur at lower SPLs, will require empirical studies similar to those reported by Thompson et al. (2013).

We also recognize that some, perhaps a majority, of bowhead whales migrating in autumn stop to feed. In that case, aversion could lead to 2 energetic costs, the cost of movement itself and the cost of a reduction in food consumption. The total energetic cost would depend on the spatial and temporal extent of the sound source and the proportion of the population affected. Alternatively, if animals feed in an area with high sound levels without averting, then the probability of biologically harmful levels of exposure might increase.

\section{Transferability and applications}

Our approach allowed us to assess the feasibility of simulating the migration of a population of $>10000$ bowhead whales over a migration period of $>2$ mo. We encountered no fundamental or intrinsic challenges to estimating aggregated acoustic exposure over extensive areas and time periods. One could adapt the model to include a greater number and variety of sound sources or apply it to different species, longer durations of simulation, or location- and season-specific life stages such as cow-calf pairs or juveniles. It would be tractable to model sound fields created by reverberation and multipath arrivals. Estimating the loss of acoustic communication space as a result of masking would require knowledge of vocalization rates, frequency band, source level, and the change in background sound spectrum due to both natural changes in ambient sound and the introduction of anthropogenic sources (see Hatch et al. 2012). By including mobile sound sources such as shipping traffic, the animat aversion model could also be adapted for proximity to vessel traffic (Ellison et al. 2012, Pirotta et al. 2015).

Our estimates of the instantaneous sound level to which individuals were exposed over time from multiple sources suggested that the presence of multiple sound sources might not substantially increase the maximum SPL to which most individuals in a given population are exposed, but may affect the duration of exposures above a given level. However, inferences might differ at higher modeled levels of industrial activity, such as a greater number of concurrent seismic surveys. Additionally, the cumulative effects of exposure to multiple sound sources may be more 
relevant at the population level on a chronic basis than at the individual level on an acute basis, particularly if the exposure includes increases in other anthropogenic activities, such as commercial shipping and other types of vessel traffic.

Although the model presented here is relatively simple, it can be modified to yield increasingly sophisticated representations of the exposure of individual animals and populations to dynamic combinations of continuous and impulsive sounds, whether anthropogenic or natural, and can be parameterized on the basis of traditional ecological knowledge or research on behaviors or behavioral responses. Accordingly, the method improves understanding of the cumulative sounds to which marine mammals are exposed. When coupled with information on bioenergetics, communication, potential habituation to certain sources of sound, and environmental covariates (e.g. distributions of prey), such analyses could begin to reduce some of the considerable uncertainty as to whether sound exposure changes population viability and whether alternative mitigation strategies may be effective. Quantitative assessments of populationlevel effects of sound are becoming a higher priority given increases in human access to and levels of activity in the Arctic, coupled with increased scrutiny of potential effects of sound on marine mammals.

Acknowledgements. This work was supported in part by a contract between BP Exploration (Alaska) Inc. and the University of California, Santa Barbara (E.F.), and by the North Slope Borough. We thank Dan Costa, Jennifer Dupont, Jason Gedamke, Jessica Lefevre, Michael Macrander, Barry Noon, Bob Pressey, Samantha Simmons, Russell Tait, Jeanette Thomas, Sandra Werner, and Gary Wolinsky for ideas and discussions that motivated and refined our work.

\section{LITERATURE CITED}

Blackwell SB, Greene J, Charles R, Richardson WJ (2004) Drilling and operational sounds from an oil production island in the ice-covered Beaufort Sea. J Acoust Soc Am 116:3199-3211

Blackwell SB, Nations CS, McDonald TL, Greene CR, Thode AM, Guerra M, Macrander AM (2013) Effects of airgun sounds on bowhead whale calling rates in the Alaskan Beaufort Sea. Mar Mamm Sci 29:E342-E365

Buck JR, Tyack PL (2000) Response of gray whales to low frequency sounds. J Acoust Soc Am 107:2774

Clark CW, Ellison WT (2004) Potential use of low-frequency sounds by baleen whales for probing the environment: evidence from models and empirical measurements. In: Thomas J, Moss C, Vater M (eds) Echolocation in bats and dolphins. University of Chicago Press, Chicago, IL, p 564-582

> Clark CW, Ellison WT, Southall BL, Hatch L, Van Parijs SM, Frankel AS, Ponirakis D (2009) Acoustic masking in marine ecosystems: intuitions, analysis, and implication.
Mar Ecol Prog Ser 395:201-222

Clarke JT, Ferguson MC (2010) Aerial surveys for bowhead whales in the Alaskan Beaufort Sea: BWASP update 2000-2009 with comparisons to historical data. Rep Int Whaling Comm SC/62/BRG14

Collins MD (1993) A split-step Padé solution for the parabolic equation method. J Acoust Soc Am 93:1736-1742

Costa DP, Crocker DE, Gedamke J, Webb PM and others (2003) The effect of a low-frequency sound (acoustic thermometry of the ocean climate) on the diving behavior of juvenile northern elephant seals, Mirounga angustirostris. J Acoust Soc Am 113:1155-1165

Council on Environmental Quality (1997) Considering cumulative effects under the National Environmental Policy Act. Council on Environmental Quality, Executive Office of the President, Washington, DC

D'Amico A, Gisiner RC, Ketten DR, Hammock JA, Johnson C, Tyack PL, Mead J (2009) Beaked whale strandings and naval exercises. Aquat Mamm 35:452-472

Davies JR (1997) The impact of an offshore drilling platform on the fall migration path of bowhead whales: a GISbased assessment. MS thesis, Western Washington University, Bellingham, WA

Department of the Navy (2001) Final overseas environmental impact statement and environmental impact statement for Surveillance Towed Array Sensor System Low Frequency Active (SURTASS LFA) Sonar. Chief of Naval Operations, Washington, DC

Dorsey EM, Richardson WJ, Würsig B (1989) Factors affecting surfacing respiration and dive behavior of bowhead whales Balaena mysticetus summering in the Beaufort Sea, Canada. Can J Zool 67:1801-1815

Ellison WT, Clark CW, Bishop GC (1987a) Potential use of surface reverberation by bowhead whales, Balaena mysticetus, in under-ice navigation: preliminary considerations. Rep Int Whaling Comm 37:329-332

Ellison WT, Sonntag RM, Clark CW (1987b) Comparison of measured bowhead whale, Balaena mysticetus, migration parameters with results from the tracking algorithm. Rep Int Whaling Comm 37:309-311

Ellison WT, Southall BL, Clark CW, Frankel AS (2012) A new context-based approach to assessing marine mammal behavioral responses to anthropogenic sounds. Conserv Biol 26:21-28

Frankel AS, Ellison WT, Buchanan J (2002) Application of the Acoustic Integration Model (AIM) to predict and minimize environmental impacts. IEEE Oceans 2002: 1438-1443

Funk DW, Ireland DS, Rodrigues R, Koski WR (eds) (2010) Joint Monitoring Program in the Chukchi and Beaufort Seas, open-water season 2006-2008. LGL Alaska Report P1050-1. Reports from LGL Alaska Research Associates, Greeneridge Sciences, and JASCO Research, for Shell Offshore, and other industry contributors, and the National Marine Fisheries Service

Gabriele CM, Clark CW, Frankel AS, Kipple BM (2010) Glacier Bay's underwater sound environment: the effects of cruise ship noise on humpback whale habitat. Alsk Park Sci 9:12-17

> George JC, Clark CW, Carroll GM, Ellison WT (1989) Observations on the ice-breaking and ice navigation behavior of migrating bowhead whales near Point Barrow, Alaska, Spring 1985. Arctic 42:24-30

George JCC, Zeh J, Suydam R, Clark C (2004) Abundance and population trend (1978-2001) of western Arctic 
bowhead whales surveyed near Barrow, Alaska. Mar Mamm Sci 20:755-773

Goldbogen JA, Southall BL, DeRuiter SL, Calabokidis J and others (2013) Blue whales respond to simulated midfrequency military sonar. Proc R Soc B Biol Sci 280: 20130657

Guerra M, Thode AM, Blackwell SB, Macrander AM (2011) Quantifying seismic survey reverberation off the Alaskan North Slope. J Acoust Soc Am 130:3046-3058

Hamilton EL (1980) Geoacoustic modeling of the sea floor. J Acoust Soc Am 68:1313-1340

Hannay DE, Racca RG (2005) Acoustic model validation. Document 0000-S-90-04-T-7006-00-E, revision 02. Technical report by JASCO Research, Victoria, BC, for Sakhalin Energy Investment Company, Yuzhno-Sakhalinsk. www.sakhalinenergy.ru/media/acd4ec1d-483c-470a-b2b7014ebde76eb3.pdf (accessed April 2016)

Hannay DE, MacGillivray AO, Laurinolli M, Racca R (2004) Sakhalin Energy: source level measurements from 2004 acoustics program, Ver. 1.5. Technical report by JASCO Research, Victoria, BC, for Sakhalin Energy Investment Company, Yuzhno-Sakhalinsk

> Hatch LT, Clark CW, Van Parijs SM, Frankel AS, Ponirakis DW (2012) Quantifying loss of acoustic communication space for right whales in and around a U.S. National Marine Sanctuary. Conserv Biol 26:983-994

> Holt MM, Noren DP, Emmons CK (2011) Effects of noise levels and call types on the source levels of killer whale calls. J Acoust Soc Am 130:3100-3106

Independent System for Peer Review (2006) Summary report: review of Acoustic Integration Model (AIM): 25-27 September 2006, Washington, DC. Prepared by Patrick Cordue, Fisheries Consultant, New Zealand, for Independent System for Peer Review, University of Miami, Miami, FL. www.nmfs.noaa.gov/pr/pdfs/permits/ lfa_aim_review.pdf (accessed April 2016)

Krutzikowsky GK, Mate BR (2000) Dive and surfacing characteristics of bowhead whales (Balaena mysticetus) in the Beaufort and Chukchi Seas. Can J Zool 78: 1182-1198

Lindquist KG, Engle K, Stahlke D, Price E (2004) Global topography and bathymetry grid improves research efforts. Eos Trans Am Geophys Union 85:186, doi: 10.1029/2004EO190003

MacGillivray AO (2006) An acoustic modeling study of seismic airgun noise in Queen Charlotte Basin. MSc thesis, University of Victoria, Victoria, BC

> Madsen PT (2005) Marine mammals and noise: problems with root mean square sound pressure levels for transients. J Acoust Soc Am 117:3952-3957

> Madsen PT, Johnson M, Miller P, Aguilar Soto N, Lynch J, Tyack P (2006) Quantitative measures of air-gun pulses recorded on sperm whales (Physeter macrocephalus) using acoustic tags during controlled exposure experiments. J Acoust Soc Am 120:2366-2379

Malme CI, Miles PR, Clark CW, Tyack PL, Bird JE (1984) Investigations of the potential effects of underwater noise from petroleum industry activities on migrating gray whale behavior, Phase II: January 1984 migration. BBN Rep. 5586 from Bolt Beranek \& Newman, Cambridge, MA for the US Minerals Management Service, Anchorage, AK

Mate BR, Krutzikowsky GK, Winsor MH (2000) Satellitemonitored movements of radio-tagged bowhead whales in the Beaufort and Chukchi Seas during the late-sum- mer feeding season and fall migration. Can J Zool 78: 1168-1181

McDonald TL, Richardson WJ, Greene CR, Blackwell SB, Nations CS, Nielson RM, Streever B (2012) Detecting changes in the distribution of calling bowhead whales exposed to fluctuating anthropogenic sounds. J Cetacean Res Manage 12:91-106

Moore SE, Reeves RR, Southall BL, Ragen TJ, Suydam RS, Clark CW (2012) A new framework for assessing the effects of anthropogenic sound on marine mammals in a rapidly changing arctic. BioScience 62:289-295

NOAA (National Oceanic and Atmospheric Administration) (2012) Mapping cetaceans and sound: modern tools for ocean management. Final report of a technical workshop held 23-24 May 2012 in Washington, DC. http:// cetsound.noaa.gov

NOAA (2013) Draft guidance for assessing the effects of anthropogenic sound on marine mammals. NOAA, Silver Spring, MD. www.nmfs.noaa.gov/pr/acoustics/draft_ acoustic_guidance_2013.pdf (accessed March 2015)

NSF-USGS (National Science Foundation-US Geological Survey) (2011) Final programmatic EIS/OEIS for marine seismic research funded by the National Science Foundation or conducted by the US Geological Survey. June 2011. Prepared for National Science Foundation, Arlington, VA, and US Geological Survey, Reston, VA

Pirotta E, Thompson PM, Cheney B, Donovan CR, Lusseau D (2015) Estimating spatial, temporal and individual variability in dolphin cumulative exposure to boat traffic using spatially explicit capture-recapture methods. Anim Conserv 18:20-31

Richardson WJ (ed) (1999) Marine mammal and acoustical monitoring of Western Geophysical's open-water seismic program in the Alaskan Beaufort Sea, 1998. Report TA2230-3 by LGL Limited, King City, ON, and Greeneridge Sciences Inc., Santa Barbara, CA, for Western Geo-physical, Houston, TX, and US National Marine Fisheries Service, Anchorage, AK, and Silver Spring, MD

> Richardson WJ, Fraker MA, Würsig B, Wells RS (1985) Behaviour of bowhead whales (Balaena mysticetus) summering in the Beaufort Sea: reactions to industrial activities. Conserv Biol 32:195-230

Richardson WJ, Greene CR, Malme CI, Thomson DH (1995a) Marine mammals and noise. Academic Press, San Diego, CA

Richardson WJ, Finley KJ, Miller GW, Davis RA, Koski WR (1995b) Feeding, social, and migration behavior of bowhead whales, Balaena mysticetus, in Baffin Bay vs. Beaufort Sea-regions with different amounts of human activity. Mar Mamm Sci 11:1-45

Rolland RM, Parks SE, Hunt KE, Castellote M and others (2012) Evidence that ship noise increases stress in right whales. Proc Biol Sci 279:2363-2368

> Roth EH, Hildebrand JA, Wiggins SM, Ross D (2012) Underwater ambient noise on the Chukchi Sea continental slope from 2006-2009. J Acoust Soc Am 131:104-110

Schick RS, Urban DL (2000) Spatial components of bowhead whale (Balaena mysticetus) distribution in the Alaskan Beaufort Sea. Can J Fish Aquat Sci 57:2193-2200

Siebert U, Dähne M, Danehl S, Meyer-Klaeden K, Wittekind D, Schuster M (2012) Kriterien und Entwicklung eines Modells zur Abschätzung des Störpotentials durch Maskierung beim Einsatz von Luftpulsern (Airguns) in der Antarktis (1. Zwischenbericht). Environmental Re- 
search of the Federal Ministry for the Environment, Nature Conservation and Nuclear Safety, Berlin

Southall BL, Bowles AE, Ellison WT, Finneran JJ and others (2007) Marine mammal noise exposure criteria: initial scientific recommendations. Aquat Mamm 33:411-521

Teague WJ, Carron MJ, Hogan PJ (1990) A comparison between the Generalized Digital Environmental Model and Levitus climatologies. J Geophys Res 95:7167-7183

Thompson PM, Brookes KM, Graham IM, Barton TR, Needham K, Bradbury G, Merchant ND (2013) Short-term disturbance by a commercial two-dimensional seismic survey does not lead to long-term displacement of

Editorial responsibility: Douglas Novacek (Guest Editor), Beaufort, Florida, USA harbour porpoises. Proc Biol Sci 280:20132001

Tyack PL, Zimmer WMX, Moretti D, Southall BL and others (2011) Beaked whales respond to simulated and actual navy sonar. PLoS One 6:e17009

Urick RJ (1983) Principles of underwater sound, 3rd edn. McGraw-Hill Book Company, New York, NY

Zhang ZY, Tindle CT (1995) Improved equivalent fluid approximations for a low shear speed ocean bottom. J Acoust Soc Am 98:3391-3396

Ziolkowski A (1970) A method for calculating the output pressure waveform from an air gun. Geophys J R Astron Soc 21:137-161

Submitted: April 20, 2015; Accepted: February 26, 2016 Proofs received from author(s): April 21, 2016 